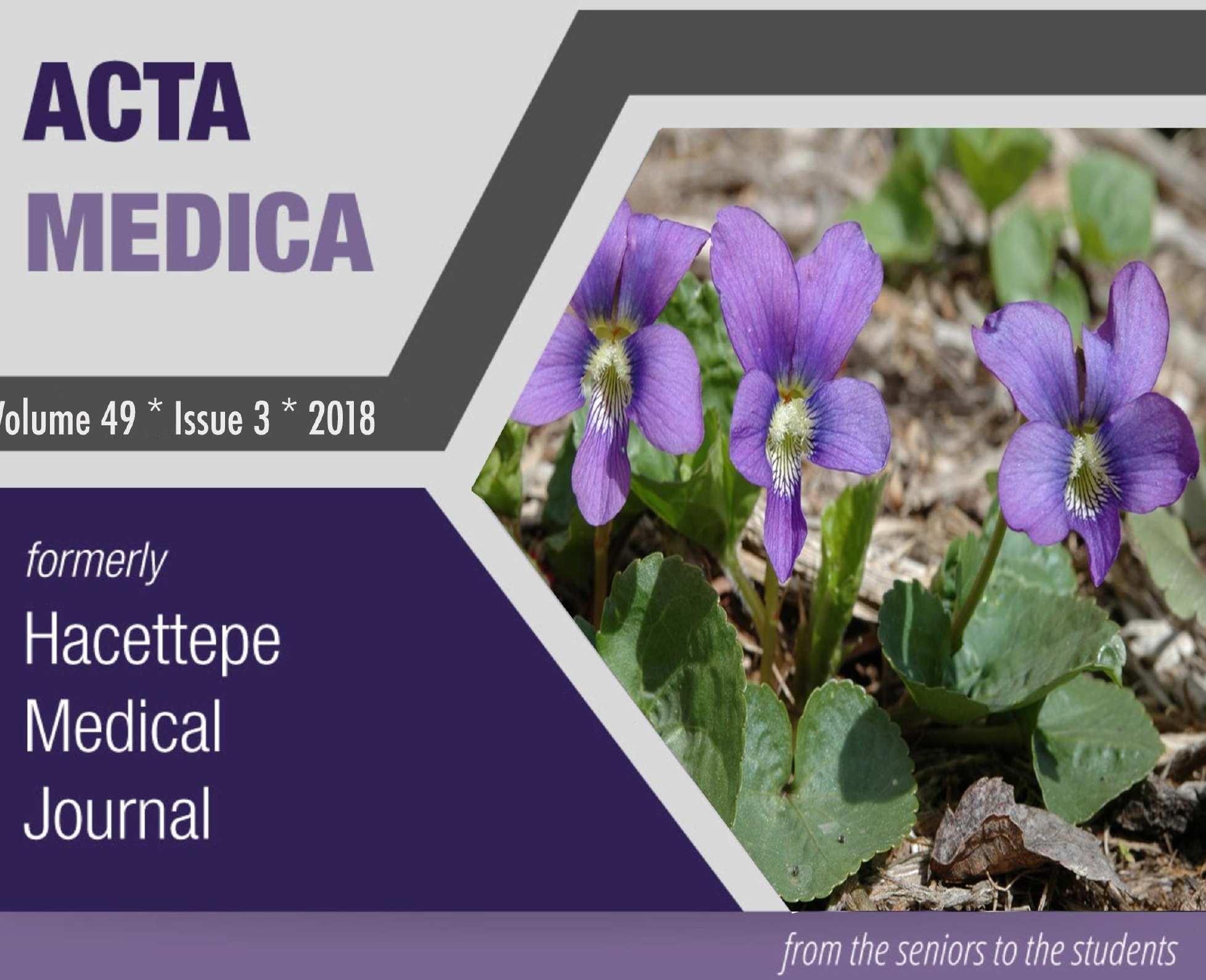




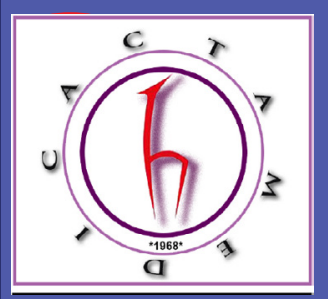

ACTA MEDICA

formerly Hacettepe Medical Journal

Volume 49; Issue;2 - 2018

\section{CONTENTS}

\section{Original Article}

- A Comparison of Thiol/Disulphide Levels of Workers in Operating Rooms and Emergency Healthcare Centers

Ethemoglu et al. $1-9$

- Risk Factors for Colonisation or Infection with Carbapenem Resistant Escherichia Coli and Klebsiella Pneumoniae

Atmis et al. $10-18$

- Circulating cell free DNA and miRNA Amount in Congenital Hearing Loss Caglar et al. $19-23$

\section{Review}

- Oxidative Stress Manifestation for Community-Acqiured Pneumonia in Children Living in Endemic Area of lodine Deficiency

Yaylacıoglu Tuncay et al. $30-40$

\section{Case Report}

- Primary Appendix Lymphoma: Case Report and Review of the Literature Ardicli et al. $41-49$

e-ISSN: 2147-9488

DOI: https://doi.org/10.32552/2018.ActaMedica.306 


\title{
A Comparison of Thiol/Disulphide Levels of Workers in Operating Rooms and Emergency Healthcare Centers
}

\begin{abstract}
Filiz Banu Ethemoglu *, [MD]
Hıdır Yılmaz ${ }^{2}$, [MD]

Gulsum Kavalci ${ }^{1}$, [MD]

Cem Akman², [MD]

Nurkan Terzioğlư ${ }^{3}$, [MD]

Havva Sahin Kavakli ${ }^{4}$, [MD]

Ozan Erel ${ }^{5},[\mathrm{MD}]$

Almina Senat ${ }^{5}$, [MD]

Ayca Koca ${ }^{2}$, [MD]

1, Yenimahalle Education and Research Hospital,

Department of Anesthesiology and Reanimation

2, Yenimahalle Education and Research Hospital,

Department of Emergency Medicine

3, Yenimahalle Education and Research Hospital Biochemistry Clinic

4, Ankara Yıldırım Beyazıt University Faculty of Medicine; Ankara Numune Education and Research Hospital Department of Emergency Medicine;

5, Atatürk Education and Research Hospital,

Biochemistry Clinic Ankara

\section{we ABSTRACT Cem}

Objective: Thiol/disulphide homeostasis has a crucial role for life. The aim of this study was to compare thiol/disulphide homeostasis in healthcare professionals working in the operating room (Group 1) and healthcare professionals working in the emergency department (Group 2).

Materials-Methods: This was a descriptive study. Fortynine operating room volunteers (Group 1) and 49 emergency department volunteers (Group 2) were included in this study. Thiol and disulphide concentrations were measured using the novel automated measurement method developed by Erel \& Neșelioğlu in 2014.

Result: The thiol/disulphide levels were compared in both groups; Native thiol in group 1 was $353,57 \pm 49,86 \mu \mathrm{mol} . \mathrm{L}^{-1}$, and it was $333,73 \pm 37,38 \mu \mathrm{mol} . \mathrm{L}^{-1}(\mathrm{p}=0.028)$ in group 2. total thiol values were 384,71 $\pm 52,36 \mu$ mol. $L \otimes^{1}$ and 370,94 15,56 $\pm 5,36$ $\mu$ mol. $\mathrm{L}^{-1}(\mathrm{P}=0,133)$, respectively in group 1 and 2 . In group 1 ,disulphide levels were $15,56 \pm 5,36 \mu \mathrm{mol} . \mathrm{L}^{-1}$, in group 2 it was $18,61 \pm 7,71 \mu \mathrm{mol} . \mathrm{L}^{-1}(\mathrm{p}=0,025)$, disulphide/ native thiol in group 1 was $4,47 \pm 1 \%$, and in group 2 it was measured $\%, 5,73 \pm 2,95 \%$ $(\mathrm{p}=0.009)$. Disulphide/total thiol in the group 1 was $4,06 \pm 1,32 \%$ and $5,03 \pm 2,13 \%$ ( $p$ $=0,008$ ) in group 2 . Native thiol $/$ total thiol levels were $90,23 \pm 12,16 \%$ in group 1 and $89,93 \pm 4,26 \%$ in group $2(p=0,871)$. Native thiol level in group 1 and high level of disulphide in group 2 indicate that the exposure to oxidative stress in the emergency department is higher than in the operating room.

Conclusion: Our results show that participants of emergency room group have statistically higher levels of disulphide than participants working in operating room which may suggest presence of oxidative stress related with workplace exposures.
\end{abstract}

*Corresponding Author: Filiz Banu Ethemoglu, Yeni-

mahalle Research and Teaching Hospital,

Department of Anesthesiology and Reanimation,

Ankara, TURKEY

DOI: https://doi.org/10.32552/2018.ActaMedica.306

e-mail: fimede@hotmail.com

Phone: +903125872077

Received: 22 June 2018, Accepted: 18 September 2018,

Published online: 30 September 2018

\section{INTRODUCTION}

The oxidative stress is caused by the domination of the oxidants due to the destruction of the balance between the antioxidant defense system of the body and free radicals. Free oxygen radicals are synthesized in small quantities in the body during normal metabolism process and do not harm the body, but they are synthesized in extreme quantities
Key Words: Health personnel, oxidative stress, thiol/disulphide homeostasis. leading to oxidative stress in some conditions such as viral diseases, exposure to ionizing radiation and environmental pollution. Also, it is suggested that free oxygen radicals (ROS) are responsible for the pathogenesis of some viral and chronic diseases [1, $2,3]$. Antioxidant defense systems have duties to prevent ROS damage on the body. Working in the 
night shift instead of the normal daytime work can lead to medical problems caused by created oxidative stress $[4,5]$. It is found that there is a correlation between the exposure to night-lights and glutathione peroxidase activity in women working at nights $[5,6]$. On the other hand, waste and leaking anesthetic gases have a significant effect on the exposure of the operating room workers, causing reproductive, neurological, hematologic, immunologic, hepatic and renal system diseases [7].

Thiols are effective in antioxidant defense procedure and thiol/disulphide homeostasis has an important role for life. Dynamic thiol/disulphide homeostasis plays a critical role in antioxidant protection, detoxification, signal transduction, apoptosis, regulation of enzymatic activity and transcription factors and cellular signaling mechanisms $[8,9]$. It is known that a number of cellular functions such as DNA and protein synthesis, protein release, cytoskeleton architecture, differentiation, apoptosis and antioxidant defense are modulated by thiol/disulphide change mechanisms of redox active thiol groups at certain stages $[9,10]$.

Thiol groups of proteins, thiol groups of low molecular weight compounds, cysteine residues and other thiol groups are oxidized by the oxidant molecules presented in the environment and turned into reversible disulphide structures. The formed disulfide structures can be reduced against to thiol groups, thereby thiol/disulphide balance can be maintained [10].

While Oxidative products give excess electrons to compounds containing thiols to be reduced, Thiol groups are oxidized and then cause the formation of the dipeptide bonds; this is a reversible reaction and dynamic thiol/disulphide balance is achieved [10]. A lot of information about the biochemical process can be obtained by measuring the dynamic thiol/disulphide homeostasis [9].

In our descriptive study, we aimed to compare the oxidative stress by measuring thiol/disulphide homeostasis levels between the emergency and the operating room staff who both have intense working hours.

\section{MATERIALS AND METHODS}

This study was conducted in Yenimahalle Education and Research Hospital between 01.01.2016 01.07.2016 after taking approval of Clinical investigations Ethical Committee (14/12/2015 - 2015/46).

This is a descriptive study. 49 operating room personnel aged 18 or older, and 49 emergency department personnel working at least six months in their units were involved in this study, as volunteers. A voluntary consent form was obtained from all participants. The personnel who had a history of smoking and immunosuppressive disease, use of immunosuppressive drugs and vitamin or mineral supplements or any antioxidant agents, any attempt or procedure under general anesthesia within the last 6 months, and any previous exposure to oxidative damage (radiology unit etc.) were not included in the study. A questionnaire consisting of 6 questions was given to all participants and the effect of the recorded variable on thiol/disulphide homeostasis was evaluated for each participant. $5 \mathrm{ml}$ of blood samples were taken from all participants in the morning and samples were stored at $-80^{\circ} \mathrm{C}$ after centrifuging in 10 minutes at $3600 \mathrm{rpm}$ in the biochemistry laboratory.

After all the samples were collected, they were all dissolved at the same time and the blood thiol / disulfide parameters were examined by Roche Hitachi Cobas 501 automatic analyzer at Ankara Atatürk Training and Research Hospital Biochemistry Laboratory by using Erel \& Neselioglu's newly developed automated measurement method [9].

Changes in the thiol level of each parameter were evaluated.

The obtained data were recorded with SPSS 11.5 and the Student t-test was used to determine the differences between the groups with normal distribution; In the case of categorical variable, ChiSquare test was used to compare two groups. The statistical boundary was given $\mathrm{p}<0.05$.

\section{RESULTS}

In our study, according to our findings, gender, age group, marital status, having children, working time, weighted diet did not affect thiol/disulphide levels statistically. Female ratio $(69,4 \%)$, greater than 40 age group ratio(42,9\%) and greater than study for 15 years time radio $(55,1 \%)$ were statistically significantly higher in group 1 than group 2 (Table 1). According to the biochemical analysis; native thiol $(353,57 \pm 49,86 \mu \mathrm{mol} / \mathrm{L})$ in group 1 ; disulphide $(18,61 \pm 7,71 \mu \mathrm{mol} / \mathrm{L})$, disulphide/native thiol $(5,73 \pm 2,95 \%)$ ratio and disulphide/total thiol $(5,03 \pm 2,13 \%)$ ratio levels in the group 2 were statistically significantly higher, but total thiol (group1: $384,71 \pm 52,36$, group $2: 370,94 \pm 36,15$ ) and native thiol/total thiol ratio (group 1: $90,23 \pm 12,16 \%$, group 2: $89,93 \pm 4,26 \%)$ were not statistically significance (Table 2). 
Table 1. Demographic characteristics of the study groups

\begin{tabular}{|c|c|c|c|}
\hline \multirow[b]{2}{*}{ Variable } & \multicolumn{2}{|c|}{ Group } & \multirow[b]{2}{*}{$P$} \\
\hline & $\begin{array}{l}\text { Operating Room } \\
(n=49) \\
n(\%)\end{array}$ & $\begin{array}{l}\text { Emergency Room } \\
\qquad \begin{array}{c}(\mathrm{n}=49) \\
\mathrm{n}(\%)\end{array}\end{array}$ & \\
\hline Gender K/E & $34 / 15(69,4)$ & $22 / 27(44,9)$ & 0,014 \\
\hline \multicolumn{4}{|l|}{ Age } \\
\hline$<30$ & $9(18,4)$ & $15(30,6)$ & \multirow{3}{*}{0,015} \\
\hline $30-39$ & $19(38,8)$ & $26(53,1)$ & \\
\hline$\Rightarrow>40$ & $21(42,9)$ & $8(16,3)$ & \\
\hline \multicolumn{3}{|l|}{ Marital status } & \multirow{3}{*}{0,170} \\
\hline Married & $39(79,6)$ & $33(67,3)$ & \\
\hline Single & $10(20,4)$ & $16(32,7)$ & \\
\hline Child owner & $36(73,5)$ & $27(55,1)$ & 0,059 \\
\hline \multicolumn{3}{|l|}{ Working hours } & \multirow{4}{*}{0,001} \\
\hline$<5$ & $5(10,2)$ & $37(75,5)$ & \\
\hline $5-14$ & $17(34,7)$ & $12(24,5)$ & \\
\hline$=>15$ & $27(55,1)$ & $0(0,0)$ & \\
\hline \multicolumn{3}{|l|}{ Type of Diet } & \multirow{4}{*}{0,310} \\
\hline Fruits and vegetables & $7(14,3)$ & $9(18,4)$ & \\
\hline Balanced & $28(57,1)$ & $20(40,8)$ & \\
\hline Meat & $6(12,2)$ & $12(24,5)$ & \\
\hline Other & $8(16,3)$ & $8(16,3)$ & \\
\hline
\end{tabular}

Table 1. Laboratory findings of the study groups

\begin{tabular}{|l|c|c|c|}
\hline \multirow{2}{*}{ Variable } & \multicolumn{2}{|c|}{ Group } & \multirow{2}{*}{} \\
\cline { 2 - 4 } & $\begin{array}{c}\text { Operating Room } \\
(\mathrm{n}=49) \\
\text { Mean } \pm \mathrm{SD}\end{array}$ & $\begin{array}{c}\text { Emergency Room } \\
(\mathrm{n}=49) \\
\text { Mean } \pm \mathrm{SD}\end{array}$ & $\mathrm{P}$ \\
\hline Native thiol $(\mu \mathrm{mol} / \mathrm{L})$ & $353,57 \pm 49,86$ & $333,73 \pm 37,38$ & 0,028 \\
\hline Total thiol $(\mu \mathrm{mol} / \mathrm{L})$ & $384,71 \pm 52,36$ & $370,94 \pm 36,15$ & 0,133 \\
\hline Disulphide $(\mu \mathrm{mol} / \mathrm{L})$ & $15,56 \pm 5,36$ & $18,61 \pm 7,71$ & 0,025 \\
\hline Disulphide/native thiol $(\%)$ & $4,47 \pm 1,56$ & $5,73 \pm 2,95$ & 0,009 \\
\hline Disulphide/total thiol $(\%)$ & $4,06 \pm 1,32$ & $5,03 \pm 2,13$ & 0,008 \\
\hline Native thiol/total thiol $(\%)$ & $90,23 \pm 12,16$ & $89,93 \pm 4,26$ & 0,871 \\
\hline
\end{tabular}

\section{DISCUSSION}

Our results show that participants of emergency room group have statistically higher levels of disulphide (or lower levels of thiol/disulphide ratio) than participants working in operating room which may suggest presence of oxidative stress related with workplace exposures. This was the first study for comparing these two groups on thiol/disulphide homeostasis.

Oxidative stress is defined as the shift of the balance between the antioxidant defense system of the body and free radicals (ROS) in favor of the oxidants [1]. Oxidative stress leads to oxidative destruction 
of lipids and other macromolecules, which results a sulfhydryl group that plays a critical role in prein the exchange of cell membranes and other cell venting the formation of oxidative stress states in components, leading to cellular necrosis and death, cells. Important thiols in the plasma are low molecresulting in tissue damage and chronic diseases [1, ular weight thiols including albumin, protein, cys2, 3]. Smoking, viral infections, inflammation, isch- teine, cysteinylglycine, glutathione, homocysteine, emia reperfusion, excessive accumulation of transi- and $\gamma^{--}$-glutamyl cysteine [9].

tion metals, cancer medications and radiation may While Oxidative products give excess electrons to increase oxidative stress [1].

compounds containing thiols to be reduced, Thiol Defense systems preventing damage in the body groups are oxidized and then cause the formation due to ROS are called Antioxidant defense systems. of dipeptide bonds; this is a reversible reaction and Although the theory of free oxygen radicals has dynamic thiol/disulphide balance is achieved [10]. been known for many years, the protective effect This balance plays a critical role in antioxidant deof antioxidants against diseases has gained impor- fense, detoxification, apoptosis, regulation of enzytance in recent years [2]. There are many different matic activity and cellular signaling. A lot of inforsubstances that can act as antioxidants. Antioxidant mation about the biochemical process can be obdefense system consists of antioxidant enzymes tained by measuring the dynamic thiol/disulphide such as superoxide dismutase (SOD), catalase (CAT), homeostasis [9]. It is known that many cellular funcglutathione peroxidase (GPx), glutathione reduc- tions such as DNA and protein synthesis, protein retase (GR), glutathione, vitamins (A, C, E), melatonin, lease, cell differentiation, apoptosis and antioxidant non-enzymatic antioxidants, and some trace ele- defense are modulated by thiol-disulfide exchange ments. Antioxidants prevent lipid peroxidation by mechanisms at certain stages [10, 11]. Abnormal inhibiting peroxidation chain reaction or by col- thiol/disulphide equilibrium levels are seen in the lecting reactive oxygen species. Antioxidants also pathogenesis of diabetes mellitus, cardiovascular have protective effects against cancer by reducing diseases, cancer, rheumatoid arthritis, chronic rethe oxidative damage to DNA and the abnormal in- nal failure, Parkinson's disease, Alzheimer's disease, crease in cell division [2, 3]. If employees work based multiple sclerosis and liver diseases.

on the shift system, changes in both cell level and Ates et al. showed that disulphide levels increased whole organism level may be seen. It is known that in patients with newly diagnosed hypertension and oxidative stress causing cellular damage is respon- patients with type 1 diabetes mellitus Also, Cakici et sible for several medical disorders. According to a al. demonstrated that disulfide levels were increased study including nurses, oxidative stress parameters in adolescent patients with newly diagnosed hyperwere shown to be increased. [4]. In addition to that, tension [12, 13, 14]. Kundi et al. found that hospital the total plasma antioxidant capacity of night work- mortality was increased in patients with a low rate ers was found to be decreased at the end of the shift of thiol/disulphide in non-ST elevated myocardicompared to the values measured during the shift al infarction [15]. Gumusyayla et al. found that the [5]. The circadian rhythm affects the antioxidant enzyme activity and the cellular mRNA levels of this enzyme [6].

level of disulphide in Alzheimer patients was significantly higher [16].

According to the results, we determined that the exOperating room personnel are exposed to infec- posure to oxidative stress was higher in the emertious agents, intensive stresses, anesthetic gases, gency service workers compared to the operating radioactive materials, chemical substances, equip- room workers. Our study is the first one to compare ment and agents that are used in the sterilization of the thiol/disulphide levels of the operating room operating room and surgical materials.

workers and emergency workers. We hope that Waste and leaking anesthetic gases are the major such studies will open the way for objective evaluoxidative stress agents exposed to operating room ations to measure for stressful and intense working workers, these cause reproductive, neurological, he- conditions in concrete terms. We believe that commatologic, immunologic, hepatic and renal system prehensive and advanced researches are needed. diseases [7]. Oxidative stress causes lipid peroxidation, oxidative damage to DNA, and degradation of the antioxidant defense system in exposed professionals [8]. Thiol is an organic compound containing The authors declare they have no conflicts of interest 
[1] McCord JM. The evolution of free radicals and oxidative stress. Am J Med 2000; 108(8): 652-59.

[2] Valko M, Leibfritz D, Moncol J, et al. Free radicals and antioxidants in normal physiological functions and human disease. Int J Biochem Cell Biol 2007; 39(1): 44-84.

[3] Kumar S. Free Radicals and Antioxidants: Human and Food System. Pelagia Research Library Advances in Applied Science Research 2011; 2(1): 129-35.

[4] Ulas T, Buyukhatipoglu $H$, Kirhan I, et al. The effect of day and night shifts on oxidative stress and anxiety symptoms of the nurses. Eur Rev Med Pharmacol Sci 2012; 16(5): 594-99.

[5] Sharifian A, Farahani S, Pasalar P, et al. Shift work as an oxidative stressor. Journal of Circadian Rhythms 2005; 3: 15.

[6] Gromadzińska J, Peplonska B, Sobala W, et al. Relationship between intensity of night shift work and antioxidant status in blood of nurses. Int Arch Occup Environ Health. 2013; 86(8): 923-30.

[7] Malekirad AA, Ranjbar A, Rahzani $K$ et al. Oxidative stress in operating room personnel: occupational exposure to anesthetic gases Human \& Experimental Toxicology 2005; 24: 597 $-601$.

[8] Lucio LMC, Braz MG, Nascimento JP, et al. Occupational hazards, DNA damage, and oxidative stress on exposure to waste anesthetic gases. Rev Bras Anestesiol 2018; 68(1): 33-41.
[9] Erel O, Neselioglu S. A novel and automated assay for thiol/disulphide homeostasis. Clin Biochem 2014; 47(18): 326-32.

[10] Comini MA. Measurement and meaning of cellular thiol: disufhide redox status. Free Radic Res 2016; 50(2): 246-71.

[11] Chianeh YR, Prabhu K. Protein thiols as an indicator of oxidative stress. Archives Medical Review Journal 2014; 23(3): 443-456.

[12] Ates I, Ozkayar N, Inan B, et al. Dynamic thiol/disulphide homeostasis in patients with newly diagnosed primary hypertension J Am Soc Hypertens 2016;10(2):159-66.

[13] Ates I, Kaplan M, Yuksel M, et al. Determination of thiol/disulphide homeostasis in type 1 diabetes mellitus and the factors associated with thiol oxidation. Endocrine 2016; 51(1): 47-51.

[14] Çakıcı EK, Eroğlu FK, Yazılıtaş F, et al. Evaluation of the level of dynamic thiol/disulphide homeostasis of in adolescent patients with newly diagnosed primary hypertension. Pediatr Nephrol 2018; 33(5): 847-53.

[15] Kundi $\mathrm{H}$, Erel Ö, Balun A. Association of thiol/disulfide ratio with syntax score in patients with NSTEMI. Scand Cardiovasc J 2015; 49(2): 95-100.

[16] Gumusyayla S, Vural G, Bektas H, et al. A novel oxidative stress marker in patients with Alzheimer's disease: dynamic thioldisulphide homeostasis. Acta Neuropsychiatr 2016; 4: 1-6. 